\title{
Peningkatan Keterampilan Guru Kimia Melalui Pembuatan Modul Praktikum Berbasis Problem Based Learning
}

\author{
Maria Erna*1, Johni Azmi², Sri Wilda Albeta ${ }^{3}$ \\ Program Studi Pendidikan Kimia FKIP, Universitas Riau, Pekanbaru \\ *e-mail: mariaerna@lecturer.unri.ac.id
}

\begin{abstract}
The skills of chemistry teachers in Rambah Hilir upstream of Rokan Hulu Regency can be improved through training in the making of chemistry practicum modules based on Problem Based Learning (PBL). Without chemistry practicums it will be difficult to learn and will be a scary lesson for students in school. For this reason chemistry teachers are needed who are skilled in making practicum modules. In this service, socialization, training and coaching have been conducted so that teachers can independently create PBL-based chemistry practicum modules. The results of the activity showed that the perception of the trainees was good, namely that $81.25 \%$ of the attitudes of the participants were categorized Very High and 18.75\% were categorized as High. Participants in this activity showed enthusiasm and activeness, mastery of the material, creativity, use of language and ways of conveying ideas still need guidance. Participants have successfully created a chemical practicum module with the subject of electrical conductivity, how to separate the mixture and test the food properly. This service is important so that teachers can apply the 2013 curriculum with a scientific approach.
\end{abstract}

Keywords: Skill, chemistry practicum module, Problem Based Learning, 2013 curriculum

\begin{abstract}
Abstrak
Keterampilan guru-guru kimia di Rambah Hilir Kabupaten Rokan Hulu dapat ditingkatkan melalui pelatihan pembuatan modul praktikum kimia berbasis Problem Based Learning (PBL). Tanpa praktikum ilmu kimia akan menjadi sulit dipelajari dan akan menjadi pelajaran yang menakutkan bagi siswa-siswa di sekolah. Untuk itu diperlukan guru-guru kimia yang terampil dalam membuat modul praktikum. Pada kegiatan pengabdian ini telah dilakukan sosialisasi, pelatihan dan pembinaan agar guru-guru dapat membuat modul praktikum kimia berbasis PBL secara mandiri. Hasil kegiatan memperlihatkan bahwa persepsi peserta pelatihan termasuk baik yaitu didapatkan 81,25\% sikap peserta berkategori Sangat Tinggi dan 18,75\% berkategori Tinggi. Peserta pada kegiatan ini memperlihatkan antusias dan keaktifan, penguasaan materi, kreatifitas, penggunaan bahasa dan cara penyampai ide masih perlu bimbingan. Peserta telah berhasil membuat modul praktikum kimia dengan pokok bahasan daya hantar listrik, cara pemisahan campuran dan uji makanan secara baik. Pengabdian ini penting dilakukan agar guru dapat menerapkan kurikulum 2013 dengan pendekatan saintifik.
\end{abstract}

Kata kunci: Keterampilan, modul praktikum kimia, Problem Based Learning, Kurikulum 2013

\section{PENDAHULUAN}

Penerapan kurikulum 2013 sangat menekankan pendekatan scientific (ilmiah) yaitu suatu kegiatan pembelajaran melalui tahapan identifikasi masalah (mengajukan pertanyaan), melakukan pengamatan, mengumpulkan data, menganalisis data, dan menarik kesimpulan hingga melakukan pengujian ulang untuk membuktikan kesimpulan (Budiani et al., 2017; Kemendikbud, 2013). Tanpa praktikum ilmu kimia akan menjadi sulit dipelajari dan akan menjadi pelajaran yang menakutkan bagi siswa-siswa di sekolah. Untuk itu diperlukan guru-guru kimia yang terampil dalam membuat modul praktikum. Hal ini sesuai dengan tuntutan dalam peraturan Kepala Lembaga Administrasi Negara No. 5 tahun 2009 yang menyatakan bahwa untuk meningkatkan kualitas pendidikan dan pelatihan Pegawai Negeri Sipil (PNS) dibutuhkan perangkat pembelajaran dalam bentuk modul (LAN, 2009). Maka modul dapat dijadikan suatu fasilitator dalam menjalankan proses pembelajaran dan mampu memotivasi peserta didik untuk lebih aktif dalam pembelajaran serta menjadikan suatu individu yang lebih mandiri (Awal et al., 2019).

Modul merupakan media pembelajaran cetak yang dirancang secara sistematis berdasarkan kurikulum tertentu dan dikemas dalam bentuk satuan pembelajaran terkecil serta 
memungkinkan dipelajari secara mandiri dalam satuan waktu tertentu agar peserta didik mampu menguasai kompetensi yang diajarkan (Prastowo, 2011). Modul berbasis Problem Based Learning $(P B L)$ merupakan salah satu jenis modul yang mengadopsi ide pokok dalam pembelajaran berbasis masalah dan menjadikannya sebagai salah satu media pembelajaran dengan mengedepankan permasalahan sebagai konteks serta daya penggerak bagi peserta didik untuk belajar baik pada pembelajaran secara teori maupun praktikum (Rosmalinda et al., 2013).

Hasil analisis situasi berdasarkan wawancara dengan guru-guru kimia yang mengikuti Pendidikan Latihan Profesional Guru Pendidikan (PLPG) pada tahun 2016 didapatkan informasi bahwa guru-guru kimia tersebut belum pernah membuat modul praktikum terintegrasi dengan teori. Biasanya mereka menggunakan Lembar Kegiatan Peserta Didik (LKPD) yang dibeli dari percetakan tertentu. Untuk itu pada kegiatan pengabdian ini akan dilakukan sosialisasi, pelatihan dan pembinaan agar guru-guru dapat membuat modul praktikum kimia berbasis $P B L$ secara mandiri. Hal ini dilakukan agar penerapan Kurikulum 2013 dapat berjalan dengan semestinya. Langkah-langkah kegiatan pengabdian yang akan dilakukan untuk meningkatkan keterampilan guru-guru kimia dalam membuat modul praktikum adalah pertama melakukan sosialisasi tentang defenisi dan kiat-kiat untuk membuat modul praktikum yang sesuai dengan keadaan sekolah, tahap kedua melatih guru-guru langsung membuat modul praktikum dan tahap ketiga membina guru-guru dengan cara membuka klinik konsultasi langsung untuk penyempurnaan produk atau media yang sudah dibuat peserta.

Metode untuk melihat peningkatan keterampilan guru dalam membuat produk modul praktikum kimia berbasis $P B L$ pada kegiatan ini adalah melakukan observasi pada saat membuat modul dan menilai produk tersebut. Untuk memotivasi peserta tim pengabdian akan menetapkan pemenangnya yaitu dari juara 1 sampai 3 dan kemudian diberi penghargaan (Warsono \& Hariyanto, 2013). Kemudian untuk menentukan respon atau sikap peserta akan dilakukan dengan cara penyebaran angket. Sasaran pengabdian ini adalah guru-guru kimia di Kecamatan Rambah Hilir Kabupaten Rokan hulu. Pengabdian ini dilakukan agar keterampilan guru-guru kimia dalam membuat modul praktikum meningkat. Diharapkan guru-guru dapat membuat, mengembangkan dan menerapkan modul praktikum kimia dalam pembelajaran secara mandiri,tepat dan cocok dengan tujuan pembelajarannya.

\section{METODE}

Peningkatan keterampilan guru-guru kimia dalam membuat modul praktikum dilakukan dalam tiga tahap. Tahap pertama sosialisasi dan pelatihan, tahap kedua workshop dan tahap ketiga pembinaan guru SMA/sederajat dalam pembuatan modul praktikum kimia berbasis $P B L$. Adapun langkah-langkah kegiatan sebagai berikut (Kelly et al., 2007).

1. Sosialisasi dan pelatihan pembuatan modul praktikum kimia berbasis $\boldsymbol{P B L}$

Sosialisasi dilakukan pada hari pertama dengan metode diskusi informasi dan Tanya jawab. Kemudian peserta dibagi dalam beberapa kelompok dengan cara menugaskan pembuatan modul praktikum kimia dan memfasilitasi dengan contoh-contoh modul praktikum kimia berbasis $P B L$. Pada tahap I akan ditentukan sikap peserta setelah mengikuti sosialisasi dan pelatihan yaitu dengan cara meganalisis deskriptif hasil angket.

2. Pembimbingan pembuatan Modul praktikum kimia (Workshop)

Pada hari kedua setiap kelompok membuat salah satu modul praktikum kimia yang dipilih langsung oleh peserta. Pokok bahasan kimia yang dapat dibuat modul praktikumnya adalah materi laju reaksi, koloid, hidrolisis garam, sifat koligatif, larutan elektrolit dan non elektrolit, Kelarutan dan hasil kelarutan dan lain-lain. Pada langkah ini dilakukan observasi keterampilan peserta dalam membuat modul.

\section{Pembinaan peserta}

Pada hari ketiga, produk modul praktikum yang dibuat oleh peserta di nilai oleh tim pengabdian dengan cara diberi reward (hadiah). Hadiah diberikan untuk membina guru-guru 
agar selalu berusaha membuat modul praktikum yang dapat diterapkan dalam pembelajaran sehari-hari.

\section{Teknik Penyelesaian Masalah}

Pemberian skor angket peserta pelatihan ditentukan berdasarkan skala Likert (Budiaji, 2013; Sugiyono, 2017) yang disusun pada Tabel 1.

Tabel 1. Bobot sikap peserta

\begin{tabular}{ccccc}
\hline \multirow{2}{*}{ Pernyataan } & \multicolumn{5}{c}{ Skor Jawaban } \\
\cline { 2 - 5 } & Sangat setuju & Setuju & Kurang Setuju & Tidak Setuju \\
\hline Positif & 4 & 3 & 2 & 1 \\
\hline Negatif & 1 & 2 & 3 & 4 \\
\hline
\end{tabular}

Untuk mengelompokkan rata-rata skor peserta kedalam tingkat sikap, terlebih dahulu ditentukan interval kelas untuk menentukan penafsiran hasil data berdasarkan nilai tertinggi-terendah dibagi jumlah total nilai $=4-1 / 5=0,6$.

Setelah diketahui besarnya interval, maka dapat ditentukan rentang skala dan kategori dari hasil angket. Nilai hasil angket diinterpretasikan (Budiaji, 2013; Sugiyono, 2017) dalam Tabel 2.

Tabel 2. Pedoman untuk interpretasi sikap peserta

\begin{tabular}{ccc}
\hline No & Kategori & Interval skor rata-rata \\
\hline 1 & Sangat rendah & $1,00-1,599$ \\
\hline 2 & Rendah & $1,60-2,199$ \\
\hline 3 & Sedang & $2,20-2,799$ \\
\hline 4 & Tinggi & $2,80-3,399$ \\
\hline 5 & Sangat Tinggi & $3,40-4,00$ \\
\hline
\end{tabular}

Adapun aspek-aspek yang diamati pada pelaksanaan pembuatan modul praktikum dapat dilihat pada Lembar obsevasi pada Tabel 3 dan rubrik nilai pada Tabel 4.

Tabel 3. Lembar observasi diskusi merancang pembuatan modul praktikum

\begin{tabular}{|c|c|c|c|c|c|c|c|c|c|c|c|c|c|}
\hline \multirow[t]{3}{*}{ No } & \multirow{3}{*}{$\begin{array}{l}\text { Aspek-aspek yang } \\
\text { dinilai }\end{array}$} & \multicolumn{12}{|c|}{ Nilai Kelompok } \\
\hline & & \multicolumn{3}{|c|}{ I } & \multicolumn{3}{|c|}{ II } & \multicolumn{3}{|c|}{ III } & \multicolumn{3}{|c|}{ IV } \\
\hline & & 1 & 2 & 3 & 1 & 2 & 3 & 1 & 2 & 3 & 1 & 2 & 3 \\
\hline 1 & $\begin{array}{l}\text { Antusias dan keaktifan } \\
\text { peserta }\end{array}$ & & & & & & & & & & & & \\
\hline 2 & Penguasaan Materi & & & & & & & & & & & & \\
\hline 3 & Kreatifitas peserta & & & & & & & & & & & & \\
\hline 4 & Penggunaan bahasa & & & & & & & & & & & & \\
\hline 5 & Cara Penyampaian & & & & & & & & & & & & \\
\hline & $\begin{array}{c}\text { Total nilai } \\
\text { Nilai }\end{array}$ & & & & & & & & & & & & \\
\hline
\end{tabular}

\section{Keterangan:}

1. Hanya satu orang yang aktif/menguasai materi/kreatif/bahasa yang baku/materi yang disampaikan detil dan jelas

2. Setengah jumlah anggota aktif/menguasai materi/kreatif/bahasa yang baku/materi yang disampaikan detil dan jelas

3. Semua anggota aktif/menguasai materi/kreatif/bahasa yang baku/materi yang disampaikan detil dan jelas. 
Tabel 4. Rubrik Nilai Lembar Observasi (Rohaman \& Lusiyana, 2017)

\begin{tabular}{cc}
\hline Nilai & Skor \\
\hline Kurang (K) & $1-5$ \\
\hline Cukup (C) & $6-10$ \\
\hline Baik (B) & $11-15$ \\
\hline
\end{tabular}

Lembar observasi dianalisis secara diskriptif untuk melihat sikap-sikap peserta selama melakukan praktek pembuatan modul praktikum.

Setiap anggota tim pengabdian bertanggung jawab mengarahkan peserta dalam pembuatan modul praktikum kimia yaitu setiap kelompok dibimbing langsung oleh 1 dosen pembimbing dan dibantu dengan mahasiswa kimia yang sedang melaksanakan kuliah kerja nyata yang lokasinya di kecamatan Rambah Hilir.

Penilaian produk modul praktikum yang dibuat peserta secara kelompok dilakukan dengan cara:

1. Setiap kelompok mempresentasi produk modul praktikum kimia berbasis $P B L$

2. Produk dinilai oleh tim pengabdian dengan menggunakan lembaran penilaian seperti pada Tabel 5.

Tabel 5. Lembar Penilaian Produk Modul Praktikum

\begin{tabular}{|c|c|c|}
\hline No & Aspek-aspek yang dinilai & $\begin{array}{l}\text { Nilai } \\
(1-4)\end{array}$ \\
\hline 1 & Kecocokan dengan tujuan pembelajaran & \\
\hline 2 & $\begin{array}{llll}\begin{array}{l}\text { Efektifitas dan } \\
\text { pembelajaran }\end{array} & \text { efisiensi } & \text { penerapan dalam } \\
\end{array}$ & \\
\hline 3 & Memotivasi dan menarik minat siswa untuk belajar & \\
\hline 4 & Tampilan modul & \\
\hline
\end{tabular}

Pemenang diberi penghargaan dengan kategori yang terdapat pada Tabel 6. Pada kegiatan ini pemenang terdiri dari juara 1 sampai 3.

Tabel 6. Kategori Penghargaan (Warsono \& Hariyanto, 2013)

\begin{tabular}{ccc}
\hline No & Kategori Penghargaan/Pemenang & $\begin{array}{c}\text { Rentangan } \\
\text { Skor Nilai }\end{array}$ \\
\hline 1 & Sangat Baik/I & $13-16$ \\
\hline 2 & Baik/II & $9-12$ \\
\hline 3 & Cukup/III & $4-8$ \\
\hline
\end{tabular}

\section{HASIL DAN PEMBAHASAN}

Berdasarkan hasil análisis angket yang diisi oleh peserta setelah dilakukan sosialisasi dan pelatihan pembuatan modul praktikum kimia berbasis PBL diperoleh dari 16 peserta yang mengisi angket terdapat 13 peserta $(81,25 \%)$ yang mempunyai sikap Sangat Tinggi dan 3 peserta $(18,75 \%)$ kategori Tinggi.

Pembuatan modul praktikum berbasis Problem Based Learning ( $P B L)$ dilakukan atas tiga tahapan yaitu tahap analisis (perencanaan), tahap desain (penulisan), dan tahap pembuatan (revisi). Pada kegiatan ini peserta pelatihan berhasil membuat Produk modul praktikum untuk 3 pokok bahasan dengan pokok bahasan daya hantar listrik, cara pemisahan campuran dan uji makanan. Modul praktikum yang dibuat berdasarkan hasil analisis kebutuhan dan kondisi. Kemudian dikembangkan desain modul praktikum yang dinilai paling sesuai dengan berbagai data dan informasi objektif yang diperoleh dari analisis kebutuhan dan kondisi (Daryanto, 2013).

Berdasarkan hasil observasi yang dilakukan pada saat peserta melakukan praktek pembuatan modul praktikum kimia berbasis PBL dapat dilihat pada Tabel 7. Terlihat setiap aspek yang diamati rata-rata setiap kelompok masuk kategori C (Cukup) (Rohaman \& Lusiyana, 2017). 
Dokumentasi peserta pengabdian dalam merancang pembuatan modul praktikum kimia berbasis PBL dapat dilihat pada Gambar 1

Tabel 7. Hasil lembar observasi

\begin{tabular}{|c|c|c|c|c|c|}
\hline \multirow[t]{2}{*}{ No } & \multirow[t]{2}{*}{ Aspek-aspek yang dinilai } & \multicolumn{4}{|c|}{ Nilai kelompok/Kategori } \\
\hline & & I & II & III & IV \\
\hline 1 & Antusias dan keaktifan peserta & $9 / \mathrm{C}$ & $9 / \mathrm{C}$ & $7 / \mathrm{C}$ & $7 / \mathrm{C}$ \\
\hline 2 & Penguasaan Materi & $7 / \mathrm{C}$ & $7 / \mathrm{C}$ & $7 / \mathrm{C}$ & $6 / \mathrm{C}$ \\
\hline 3 & Kreatifitas peserta & $7 / \mathrm{C}$ & $10 / \mathrm{C}$ & $6 / \mathrm{C}$ & $6 / \mathrm{C}$ \\
\hline 4 & Penggunaan bahasa & $7 / \mathrm{C}$ & $7 / C$ & $6 / \mathrm{C}$ & $7 / \mathrm{C}$ \\
\hline 5 & Cara Penyampaian ide & $6 / \mathrm{C}$ & $5 / \mathrm{K}$ & $5 / \mathrm{K}$ & $6 / C$ \\
\hline & $\begin{array}{l}\text { Total nilai } \\
\text { Nilai }\end{array}$ & $\begin{array}{c}36 \\
7,2 / \mathrm{C}\end{array}$ & $\begin{array}{c}38 \\
7,6 / C\end{array}$ & $\begin{array}{c}31 \\
6,2 / C\end{array}$ & $\begin{array}{c}32 \\
6,5 / C\end{array}$ \\
\hline
\end{tabular}

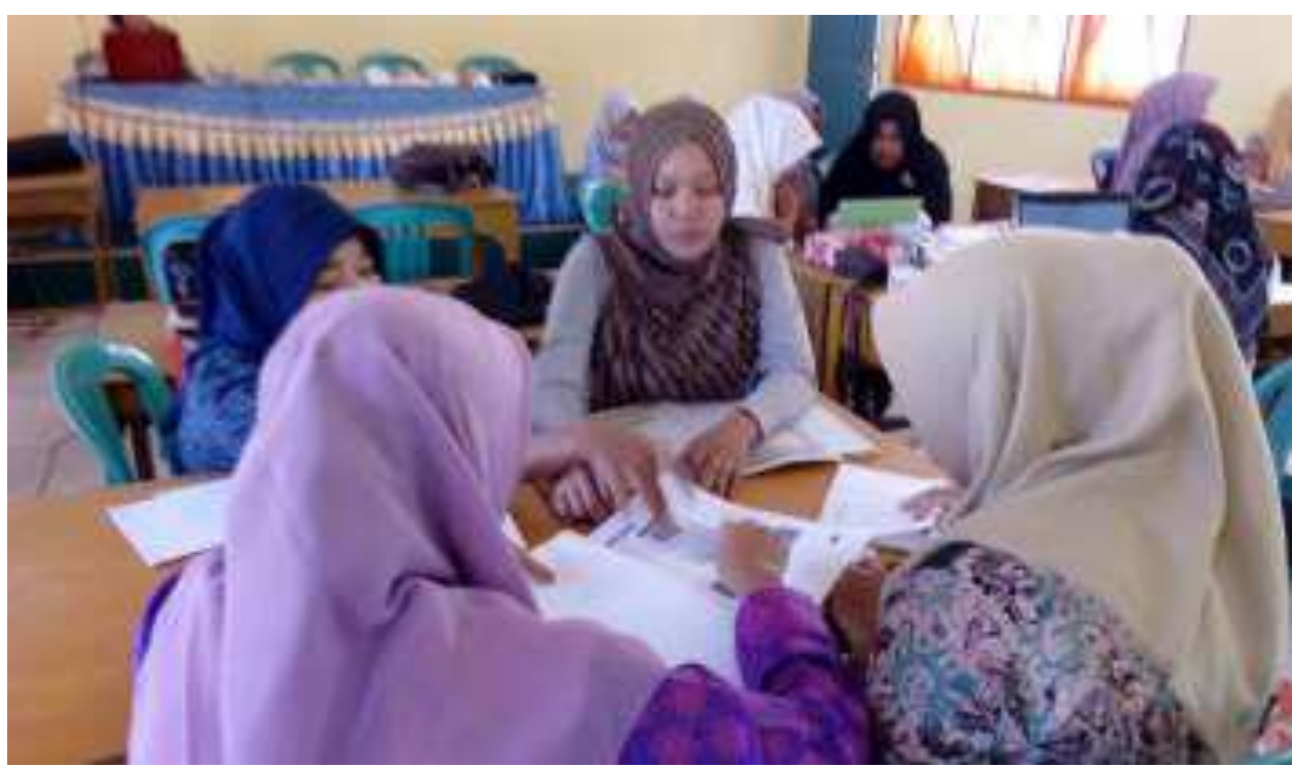

Gambar 1. Peserta pengabdian berdiskusi secara kelompok merancang modul praktikum

Produk yang dihasilkan dari pelatihan ini adalah modul praktikum kimia berbasis Problem Based Learning (PBL). Modul yang telah dibuat, direvisi dan dikumpulkan oleh peserta terdapat 3 buah modul dengan pokok bahasan daya hantar listrik (I), cara pemisahan campuran (II) dan uji makanan (III). Adapun nilai produk dapat dilihat pada Tabel 8. Terlihat bahwa Kelompok I sebagai pemenang I, kelompok III sebagai pemenang II dan kelompok II sebagai pemenang III. Cover modul praktikum pemenang I dapat dilihat pada Gambar 2.

Tabel 8. Nilai Produk Modul Praktikum

\begin{tabular}{|c|c|c|c|c|}
\hline \multirow{2}{*}{ No } & \multirow{2}{*}{ Aspek-aspek yang dinilai } & \multicolumn{3}{|c|}{ Nilai } \\
\hline & & I & II & III \\
\hline 1 & Kecocokan dengan tujuan pembelajaran & 4 & 4 & 4 \\
\hline 2 & Efektifitas dan efisiensi penerapan dalam pembelajaran & 4 & 3 & 4 \\
\hline 3 & Memotivasi dan menarik minat siswa untuk belajar & 4 & 3 & 3 \\
\hline 4 & Tampilan modul & 3 & 2 & 3 \\
\hline & Nilai total/Penghargaan & 15/SB & 12/B & $14 / \mathrm{SB}$ \\
\hline
\end{tabular}

Modul praktikum kimia berbasis Problem Based Learning (PBL) yang dibuat peserta terbagi atas tiga bagian utama yakni (Sukiman, 2012): 
a. Bagian pendahuluan yang terdiri dari judul, kata pengantar, daftar isi, peta kedudukan modul, deskripsi modul, petunjuk penggunaan modul, tata tertib laboratorium dan chemlabs basic.

b. Bagian inti yang terdiri dari materi dalam bentuk wacana, kegiatan praktikum asam basa, latihan dan soal (pre lab dan post lab).

c. Bagian penutup yang terdiri dari evaluasi, glosarium, daftar pustaka, kunci jawaban dan umpan balik.

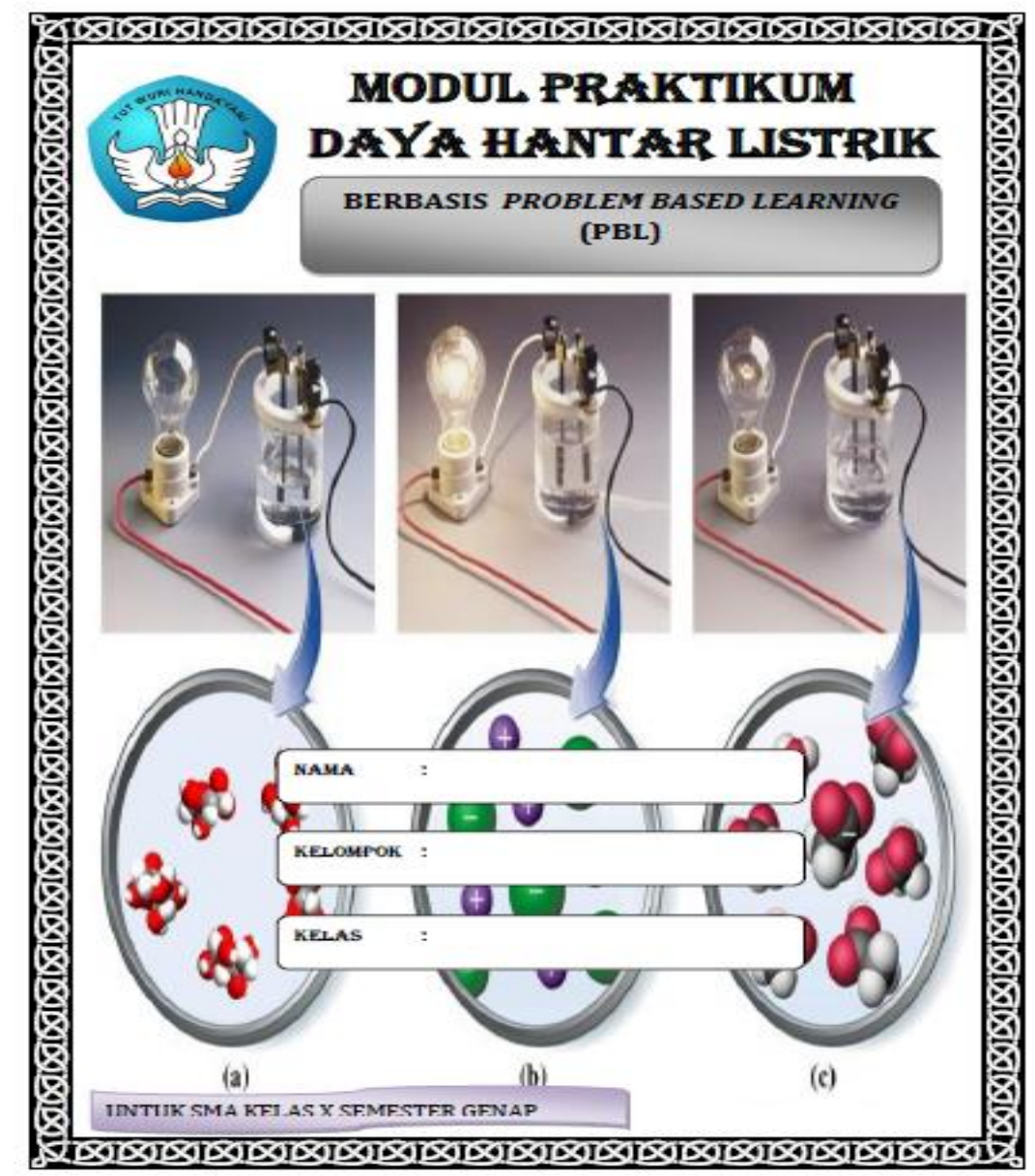

Gambar 2. Cover modul praktikum daya hantar listrik berbasis PBL

Produk modul praktikum kimia dibuat melalui pembuatan outline dilanjutkan ke tahap penulisan draft modul praktikum. Pada penulisan draft modul praktikum peserta dibimbing oleh dosen melalui tahap perencanaan, pembuatan dan revisi. Revisi sesuai dengan saran dan arahan dari dosen pembimbing melalui konsultasi yang dilakukan via email atau whatsApp.

Adapun materi yang didiskusikan antara peserta dengan dosen pembimbing dalam pembuatan modul praktikum kimia berbasis problem based learning adalah mulai dari judul materi, petunjuk penggunaan, isi, instruksi pendukung, kerangka penyajian, wacana (permasalahan yang mengarah kepada materi dan kegiatan pada modul), kegiatan praktikum, tugas atau latihan soal, kata motivasi (quotes), kunci jawaban, glosarium dan referensi yang digunakan modul praktikum (daftar pustaka). Sesuai dengan Prastowo, modul setidaknya mempunyai beberapa komponen yakni judul, kompetensi dasar, latihan, lembar kegiatan, informasi pendukung dan evaluasi (Prastowo, 2011) 


\section{KESIMPULAN} berikut:

Berdasarkan hasil dan pembahasan kegiatan pengabdian ini dapat disimpulkan sebagai

1. Peserta yang mengikuti kegiatan ini memperlihatkan persepsi yang baik yaitu didapatkan $81,25 \%$ sikap peserta terhadap kegiatan berkategori Sangat Tinggi dan 18,75\% berkategori Tinggi.

2. Peserta pada kegiatan ini memperlihatkan antusias dan keaktifan, penguasaan materi, kreatifitas, penggunaan bahasa dan cara penyampai ide masih perlu bimbingan.

Peserta telah berhasil membuat modul praktikum kimia dengan pokok bahasan daya hantar listrik, cara pemisahan campuran dan uji makanan secara baik.

\section{UCAPAN TERIMA KASIH}

Terima kasih kepada Lembaga Penelitian dan Pengabdian Kepada Masyarakat (LPPM) Universitas Riau yang telah membiayai kegiatan pengabdian ini melalui dana DIPA Universitas Riau.

\section{DAFTAR PUSTAKA}

Awal, R., Wahyuni, S., \& Sari, M. (2019). Pelatihan Penggunaan Aplikasi Edmodo Bagi Guru SMP dan SMA Smart Indonesia Pekanbaru. DINAMISIA-Jurnal Pengabdian Kepada Masyarakat, $3(1), 69-75$.

Budiaji, W. (2013). Skala Pengukuran dan Jumlah Respon Skala Likert. Jurnal Ilmu Pertanian Dan Perikanan, 2, 127-133.

Budiani, S., Sudarmin, \& Syamwil, R. (2017). Evaluasi Implementasi Kurikulum 2013 di Sekolah Pelaksana Mandiri. Innovative Journal of Curriculum and Educational Technology, 6, 45-57.

Daryanto. (2013). Menyusun Modul. Gava Media.

Kelly, M., Davey, H., \& Haigh, N. (2007). Use of the Action-Research Methodology in the Development of Accounting Education. Accounting Educators' Journal, 11, 42-48.

Kemendikbud. (2013). Konsep Pendekatan Saintifik. Kementerian Pendidikan dan Kebudayaan RI. LAN. (2009). Peraturan Kepala Lembaga Administrasi Negara Nomor: 5 tahun 2009. Lembaga Administrasi Negara.

Prastowo, A. (2011). Panduan Kreatif Membuat Bahan Ajar Inovatif. Diva Press.

Rohaman, F., \& Lusiyana, A. (2017). Pengembangan Modul Praktikum Mandiri Sebagai Asesmen Keterampilan Proses Sains dan Keterampilan Sosial Mahasiswa. Jurnal Inovasi Pendidikan Fisika Dan Riset Ilmiah, 1, 47-56.

Rosmalinda, D., Rusdi, M., \& Hariyadi, B. (2013). Pengembangan Modul Praktikum Kimia SMA Berbasis PBL (Problem Based Learning). Edu-Sains, 2, 1-7.

Sugiyono. (2017). Metode Penelitian Pendidikan. Alfabeta.

Sukiman. (2012). Pengembangan Media Pembelajaran. Pedajogja.

Warsono, \& Hariyanto. (2013). Pembelajaran Aktif: Teori dan Assesment. PT. Remaja Rosdakarya. 